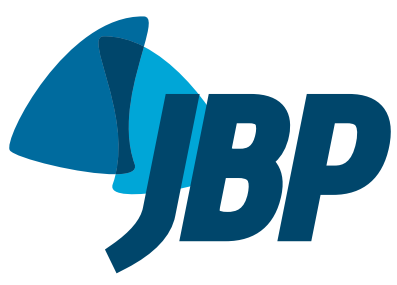

1. Programa de Pós-Graduação em Medicina, Universidade Federal de Ciências da Saúde de Porto Alegre, Porto Alegre (RS) Brasil.

2. Universidade Federal do Rio Grande do Sul, Porto Alegre (RS) Brasil.

3. Universidade Federal do Rio de Janeiro, Rio de Janeiro (RJ) Brasil.

Submitted: 31 August 2016. Accepted: 4 May 2017

Study carried out at the Universidade Federal de Ciências da Saúde de Porto Alegre, Universidade Federal do Rio Grande do Sul, Porto Alegre (RS) e Universidade Federal do Rio de Janeiro, Rio de Janeiro (RJ) Brasil.

\title{
Chest CT findings in patients with dysphagia and aspiration: a systematic review
}

\author{
Betina Scheeren ${ }^{1}$, Erissandra Gomes ${ }^{2}$, Giordano Alves ${ }^{3}$, Edson Marchiori ${ }^{3}$, \\ Bruno Hochhegger ${ }^{1}$
}

\begin{abstract}
The objective of this systematic review was to characterize chest CT findings in patients with dysphagia and pulmonary aspiration, identifying the characteristics and the methods used. The studies were selected from among those indexed in the Brazilian Virtual Library of Health, LILACS, Indice Bibliográfico Español de Ciencias de la Salud, Medline, Cochrane Library, SciELO, and PubMed databases. The search was carried out between June and July of 2016. Five articles were included and reviewed, all of them carried out in the last five years, published in English, and coming from different countries. The sample size in the selected studies ranged from 43 to 56 patients, with a predominance of adult and elderly subjects. The tomographic findings in patients with dysphagia-related aspiration were varied, including bronchiectasis, bronchial wall thickening, pulmonary nodules, consolidations, pleural effusion, ground-glass attenuation, atelectasis, septal thickening, fibrosis, and air trapping. Evidence suggests that chest CT findings in patients with aspiration are diverse. In this review, it was not possible to establish a consensus that could characterize a pattern of pulmonary aspiration in patients with dysphagia, further studies of the topic being needed.
\end{abstract}

Keywords: Respiratory aspiration; Tomography, X-ray computed; Lung.

\section{INTRODUCTION}

The epidemiology of aspiration syndromes is not well described in the literature because of the lack of specificity and sensitivity markers; however, the literature indicates that $5-15 \%$ of the cases of community-acquires pneumonia are due to aspiration. ${ }^{(1)}$ Lung injury caused by aspiration of saliva or food particles can often result from dysphagia. ${ }^{(2,3)}$ Dysphagia can be of neurogenic, mechanical, or psychogenic origin and manifests itself through a series of signs and symptoms, such as cough, choking, and pharyngeal globus, being a major risk factor for malnutrition, dehydration, and aspiration pneumonia. ${ }^{(4-6)}$

Evaluation of dysphagia involves clinical evaluation and speech pathology assessment, as well as ancillary tests, such as videofluoroscopic swallowing study (VFSS) and fiberoptic endoscopic evaluation of swallowing (FEES), which serve to aid in the diagnosis of swallowing disorders, such as aspiration. ${ }^{(7-9)}$ In contrast, chest CT is used to evaluate pulmonary lesions, being of great importance in the diagnosis of aspiration disorders, since pulmonary symptoms can be the first manifestation of aspiration. ${ }^{(10)}$

Imaging findings of aspiration are numerous and usually nonspecific, pulmonary infection being the most serious complication of aspiration. ${ }^{(10,11)}$ Therefore, knowledge about the different types of pulmonary aspiration is important for drawing correlations between the clinical information and the main CT findings, including diffuse aspiration bronchiolitis, aspiration pneumonitis, aspiration pneumonia, foreign body aspiration, and exogenous lipoid pneumonia. (11) By specifically detailing the imaging findings of aspiration pneumonia, segmental or lobar airspace consolidation can be observed, which may or may not be associated with pleural effusion. ${ }^{(11)}$

Knowledge about the CT findings of aspiration is essential for establishing the diagnosis of aspiration disorders and for attempting to prevent lung injury. Here, we aimed to perform a systematic literature review of chest CT findings that characterize pulmonary aspiration in patients with dysphagia, identifying the characteristics and the methods used.

\section{METHODS}

\section{Research strategies}

This systematic review followed the recommendations of the latest version of the Cochrane Handbook for Systematic Reviews of Interventions, ${ }^{(12)}$ which involve formulating the research question, finding and selecting scientific articles, and critically assessing the selected articles. The research question used was: "What chest CT image findings are diagnostic markers of aspiration in patients with dysphagia?" The review was developed by three researchers, two of whom searched for articles independently and blindly and one of whom was assigned as a reviewer, being consulted in cases of uncertainty so as to establish agreement. All of the researchers involved-two speech-language pathologists and one

Correspondence to:

Betina Scheeren. Rua Teixeira Mendes, 187, apto. 301, Chácara das Pedras, CEP 90050-170, Porto Alegre, RS, Brasil.

Tel.: 5551 9725-8226. E-mail: betinascheeren@hotmail.com

Financial support: None. 
radiologist who works in thoracic radiology-have over $10 y e a r s$ of clinical and practical experience in the study area. Studies were selected by using the following search terms: "pneumonia aspirativa" and "aspiration pneumonia"; "aspiração" and "aspiration"; "pulmonar" and "pulmonary"; and "tomografia computadorizada" and "computed tomography". These search terms were obtained from DeCS and MeSH and were used to search the Brazilian Virtual Library of Health, LILACS, Indice Bibliográfico Español de Ciencias de la Salud, Medline, Cochrane Library, SciELO, and PubMed online databases. The search was carried out between June and July of 2016, on the basis of the intersection of the chosen search terms.

\section{Selection criterion}

Studies in humans, written in English, Portuguese, or Spanish, regardless of the publication year, and whose title, abstract, or body of text contained any of the search terms chosen for this review were selected. Studies mentioning aspiration of food particles into the upper digestive tract and chest CT were included. Repeated studies were excluded, as were studies whose abstracts or full texts were not found in the databases consulted, review articles, dissertations, theses, case studies, and studies in which the underlying disease was tuberculosis. No search filters were applied. The article selection process is described as a flowchart in Figure 1, as recommended in the PRISMA statement. ${ }^{(13)}$

\section{Data analysis}

After the abstracts of the studies found were selected, the full texts of the articles were retrieved. After full text reading, the following data were extracted: names of the authors; year of publication; country where the study was conducted; study design; study subjects; sample size; diagnostic tests used; underlying disease; and chest CT findings, which were defined in accordance with the glossary of terms for thoracic imaging from the Fleischner Society. ${ }^{(14)}$

\section{RESULTS}

Five articles were selected for inclusion in the present systematic review, all of them carried out in the last 5 years, published in English, and coming from different countries (Italy, USA, Japan, China, and Brazil; Table 1). Sample sizes in the studies ranged from 43 to 56 patients, the predominant population being adults (19-59 years) and elderly subjects ( $\geq 60$ years).

Most of the studies evaluated in this review had a retrospective, cross-sectional design. ${ }^{(15-18)}$ The sample characteristics varied. The patients studied had laryngeal cancer, ${ }^{(15)}$ acute pneumonia associated with dysphagia, ${ }^{(16)}$ or chronic aspiration, ${ }^{(17,18)}$ and a study of healthy subjects assessed the presence or absence of aspiration. ${ }^{(19)}$ The diagnostic tests used in the studies were VFSS, ${ }^{(15,16,18)}$ FEES, ${ }^{(15,19)}$ bronchoscopy ${ }^{(17)}$ HRCT, $^{(15)}$ and conventional CT. ${ }^{(16-19)}$

The CT findings in patients with dysphagia-related aspiration were varied, including emphysema, ${ }^{(15)}$ bronchiectasis, ${ }^{(15,16,19)}$ bronchial wall thickening, ${ }^{(15,16,18,19)}$ nodules, $(15,16,18)$ tree-in-bud pattern, $(15,19)$ consolidation, (15-18) pleural effusion, ${ }^{(15-17)}$ groundglass attenuation, ${ }^{(15,16,18)}$ septal thickening, ${ }^{(15,16)}$ cavitary lesions, ${ }^{(15)}$ lymph nodes, ${ }^{(15)}$ atelectasis, ${ }^{(16-18)}$ bronchiolectasis, ${ }^{(18,19)}$ fibrosis, ${ }^{(19)}$ and air trapping. ${ }^{(18,19)}$ One of the studies demonstrated a higher frequency of findings in the right lung, ${ }^{(17)}$ and two found changes that were more prevalent in lower lung zones. ${ }^{(16,18)}$ In the study by Simonelli et al., (15) it was not possible to describe the proportion of findings, because they

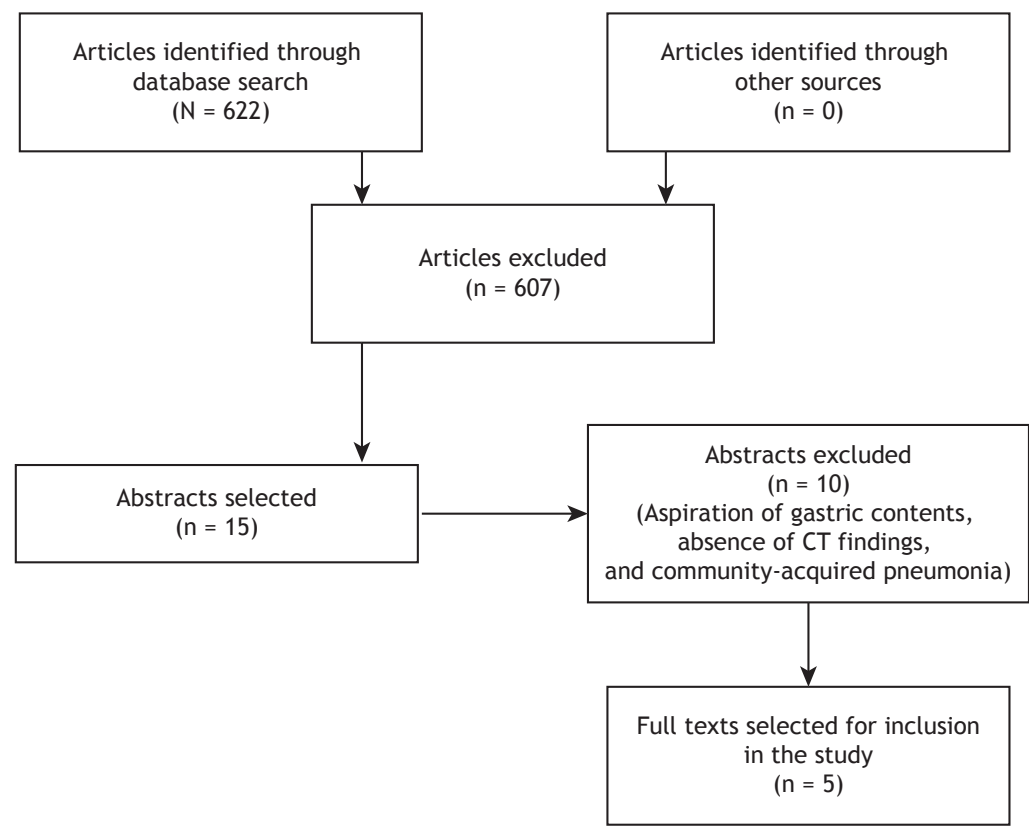

Figure 1. Article selection flowchart of the present systematic review. 
Table 1. Characteristics of the selected articles.

\begin{tabular}{|c|c|c|c|c|c|c|c|}
\hline Study & Year & Country & Population & $\begin{array}{l}\text { Study } \\
\text { design }\end{array}$ & $\begin{array}{l}\text { Sample size and } \\
\text { characteristics }\end{array}$ & $\begin{array}{l}\text { Diagnostic } \\
\text { tests used }\end{array}$ & Chest CT findings \\
\hline $\begin{array}{l}\text { Simonelli } \\
\text { et al. }{ }^{(15)}\end{array}$ & 2010 & Italy & $A / G$ & RS & $\begin{array}{l}45 \text { patients } \\
\text { after partial } \\
\text { laryngectomy } \\
\text { (mean age }=67 \\
\text { years; } 92.2 \% \text { men) } \\
\text { and } 45 \text { controls } \\
\text { (patients with } \\
\text { COPD and normal } \\
\text { swallowing) }\end{array}$ & $\begin{array}{l}\text { FEES, VFSS, } \\
\text { and HRCT }\end{array}$ & $\begin{array}{l}\text { Emphysema; bronchiectasis; } \\
\text { bronchial wall thickening; } \\
\text { pulmonary nodules or } \\
\text { cysts; tree-in-bud pattern; } \\
\text { consolidation; pleural effusion; } \\
\text { septal thickening; cavitary } \\
\text { lesions; and lymph nodes }\end{array}$ \\
\hline $\begin{array}{l}\text { Komiya } \\
\text { et al. }{ }^{(16)}\end{array}$ & 2013 & Japan & G & RS & $\begin{array}{l}53 \text { patients } \\
\text { admitted to the } \\
\text { hospital with } \\
\text { pneumonia and } \\
\text { dysphagia (mean } \\
\text { age = } 84 \text { years; } \\
66 \% \text { of men) }\end{array}$ & $\begin{array}{l}\text { VFSS and } \\
\text { conventional } \\
\text { CT }\end{array}$ & $\begin{array}{l}\text { Centrilobular nodules }(74 \%) ; \\
\text { ground-glass attenuation } \\
(74 \%) ; \text { peribronchovascular } \\
\text { thickening }(42 \%) \text {; airspace } \\
\text { consolidation }(34 \%) \text {; atelectasis } \\
(17 \%) \text {; septal thickening }(13 \%) ; \\
\text { pleural effusion (13\%); and } \\
\text { traction bronchiectasis }(2 \%)\end{array}$ \\
\hline $\begin{array}{l}\text { Lin et } \\
\text { al. }{ }^{(17)}\end{array}$ & 2014 & China & $A / G$ & RS & $\begin{array}{l}43 \text { patients with } \\
\text { aspiration }(G= \\
17 ; A=26 ; \text { mean } \\
\text { age = } 56 \text { years; } \\
70 \% \text { of men) }\end{array}$ & $\begin{array}{l}\text { Bronchoscopy } \\
\text { and } \\
\text { conventional } \\
\text { CT }\end{array}$ & $\begin{array}{l}{ }^{a} \text { Consolidation }(93 \% / 92 \%) ; \\
\text { atelectasis }(14 \% / 23 \%) ; \\
\text { high-density airway lesion } \\
(29 \% / 4 \%) \text {; pleural effusion } \\
(0 \% / 8 \%) ; \text { foreign body - food } \\
\text { particles - }(21 \% / 35 \%) \text { : left } \\
\text { lung }(35 \% / 31 \%) \text { and right lung } \\
(65 \% / 69 \%)\end{array}$ \\
\hline $\begin{array}{l}\text { Butler } \\
\text { et al. }{ }^{(19)}\end{array}$ & 2014 & USA & G & PS & $\begin{array}{l}50 \text { healthy } \\
\text { patients divided } \\
\text { into } 2 \text { groups: } \\
\text { aspirators ( } \mathrm{n}= \\
25 ; \text { mean age } \\
=77 \text { years; } 15 \\
\text { women) and } \\
\text { non-aspirators ( } \mathrm{n} \\
=25 ; \text { mean age = } \\
76 \text { years; } 16 \text { men) }\end{array}$ & $\begin{array}{l}\text { FEES and } \\
\text { conventional } \\
\text { CT }\end{array}$ & $\begin{array}{l}\text { 'Bronchiectasis }(2 \% / 8 \%) \text {; } \\
\text { bronchiolectasis }(10 \% / 6 \%) \text {; } \\
\text { bronchial wall thickening } \\
\text { ( } 22 \% / 12 \%) \text {; parenchymal band } \\
(8 \% / 4 \%) \text { fibrosis }(16 \% / 16 \%) ; \\
\text { air trapping }(20 \% / 26 \%) ; \\
\text { intraluminal airway debris } \\
(6 \% / 8 \%) \text {; and tree-in-bud } \\
\text { pattern }(6 \% / 4 \%) \\
\text { p }>0.05 \text { for all }\end{array}$ \\
\hline $\begin{array}{l}\text { Scheeren } \\
\text { et al. }{ }^{(18)}\end{array}$ & 2016 & Brazil & $A / G$ & RS & $\begin{array}{l}56 \text { patients } \\
\text { divided into } \\
2 \text { groups: } \\
\text { non-aspirators } \\
\text { and aspirators } \\
\text { ( } \mathrm{n}=28 \text { in each } \\
\text { group; mean age } \\
=65 \text { years; } 29 \\
\text { men) }\end{array}$ & $\begin{array}{l}\text { VFSS and } \\
\text { conventional } \\
\text { CT }\end{array}$ & $\begin{array}{l}\text { 'Bronchial wall thickening } \\
(54 \% / 53 \%)^{*} \text {; bronchiolectasis } \\
(15 \% / 0 \%)^{* *} \text {; centrilobular } \\
\text { nodules }(16 \% / 4 \%)^{* *} \text {; ground- } \\
\text { glass attenuation }(4 \% / 0 \%)^{* *} ; \\
\text { atelectasis }(18 \% / 2 \%)^{* *} ; \\
\text { consolidation }(6 \% / 0 \%)^{* *} \text {; and } \\
\text { air trapping }(54 \% / 53 \%)^{*} \\
{ }^{*} p=0.208 ;{ }^{* *} p<0.001\end{array}$ \\
\hline
\end{tabular}

A: adult; G: geriatric: RS: retrospective study; FEES: fiberoptic endoscopic evaluation of swallowing; VFSS: videofluoroscopic swallowing study; and PS: prospective study. ${ }^{\mathrm{a}} \mathrm{G}$ patients/A patients. ${ }^{\mathrm{b}} \mathrm{Aspirators} / \mathrm{non}$-aspirators.

were reported by degree of aspiration. It is of note that, in two studies, aspirators and non-aspirators were compared. ${ }^{(18,19)}$

\section{DISCUSSION}

The selection, reading, and analysis of articles revealed that there have been few studies attempting to define a pattern of chest $\mathrm{CT}$ findings related to dysphagiarelated pulmonary aspiration. The five articles selected in the present review were published in the last 5 years, which may explain the recent concern over early identification of patients with dysphagia who aspirate and over strategies that may intervene in the etiology. One study found a significant correlation between the degree of dysphagia and the relative risk of pneumonia, demonstrating that patients with tracheal aspiration are ten times more likely to develop pneumonia than individuals with normal swallowing. ${ }^{(20)}$

The most serious complication associated with aspiration in patients with dysphagia is pulmonary infection. ${ }^{(10)}$ Studies indicate aspiration pneumonia as a cause of community-acquired pneumonia. ${ }^{(21,22)}$ It is important to note that, in addition to the respiratory 
complication, the swallowing disorder is a risk factor for malnutrition and functional decline. ${ }^{(23)}$ Aspiration pneumonia is the leading cause of death in patients with dysphagia, a condition that affects 300,000-600,000 people per year in the USA. ${ }^{(1)}$

Simonelli et al. ${ }^{(15)}$ addressed the relationship between dysphagia and aspiration in laryngectomized patients, compared with a control group of patients with COPD, and found no significant differences in radiological findings between the groups. It is currently known that patients with COPD have dysphagia symptoms related to airway protection because of changes in the breathing pattern and in the coordination of swallowing and breathing, leading to a greater likelihood of developing pneumonia.(24) It should be noted here that, of the 116 patients selected for the study, ${ }^{(15)}$ only 45 had aspiration by VFSS and then underwent chest CT scans to assess the radiological manifestations of aspiration. In the two groups, the findings with the highest incidence rates were bronchial wall thickness, bronchiectasis, nodules, emphysema, consolidation, and septal thickening, with rates varying according to the degree of aspiration in the study group.

In the study by Komiya et al.,(16) the pulmonary CT findings were described in patients with an acute condition, that is, presenting with pneumonia at hospital admission, and dysphagia was confirmed by VFSS. The most frequent chest CT findings were airspace consolidation, ground-glass attenuation, centrilobular nodules, and peribronchovascular thickening. Pulmonary opacities predominated in lower or diffuse areas of the lung and were distributed posteriorly. The authors did not enroll a control group (without dysphagia/ aspiration). In the study, ${ }^{(16)}$ there was a predominance of elderly patients (geriatric population), among whom the risk of aspiration of oropharyngeal secretions and food particles is increased. ${ }^{(25)}$ There is evidence in the literature that the frequency of dysphagia is higher in the elderly, and aspiration is an important etiologic factor leading to pneumonia in this population. ${ }^{(26)}$
One of the studies analyzed in the present review did not use ancillary tests to assess swallowing or detect dysphagia; the presence of acute aspiration of large food particles was identified solely by bronchoscopy. (17) The most prevalent chest CT findings in the study were consolidation, atelectasis, and high-density airway lesion, predominantly in the right lung and lower lobe. ${ }^{(17)}$

In the study by Butler et al. ${ }^{(19)}$ aspiration status was prospectively evaluated by administering liquid boluses, and other bolus consistencies were not used, which could result in an increased number of pulmonary imaging findings. In addition, the authors did not use VFSS, which is considered the gold standard for detecting aspiration, choosing to use FEES. FEES is an exam that is performed with a nasal endoscope and allows direct observation and evaluation of laryngopharyngeal structures, as well as of swallowing; however, aspiration can only be observed after the swallow, through visualization of the presence of dyed food particles in the trachea. ${ }^{(27)}$ The authors did not find significant differences in the radiological pattern between the case and control groups, the findings being bronchiectasis, bronchiolectasis, bronchial wall thickening, air trapping, and fibrosis. ${ }^{(19)}$

The most recent study addressing pulmonary findings in patients with chronic aspiration ${ }^{(18)}$ included patients with and without aspiration diagnosed by VFSS who underwent chest CT. A comparison of the two groups revealed that the patients with aspiration had a higher frequency of changes such as atelectasis, centrilobular nodules, bronchiolectasis, consolidation, and ground-glass attenuation. Bronchial wall thickening and air trapping were the most prevalent findings in both groups; however, no significant differences were demonstrated. In addition, the authors reported that the findings were more prevalently distributed in lower lung zones. Figures 2 and 3 exemplify some of the CT findings described.

One of the limitations of the present systematic review was the lack of articles published on the subject,
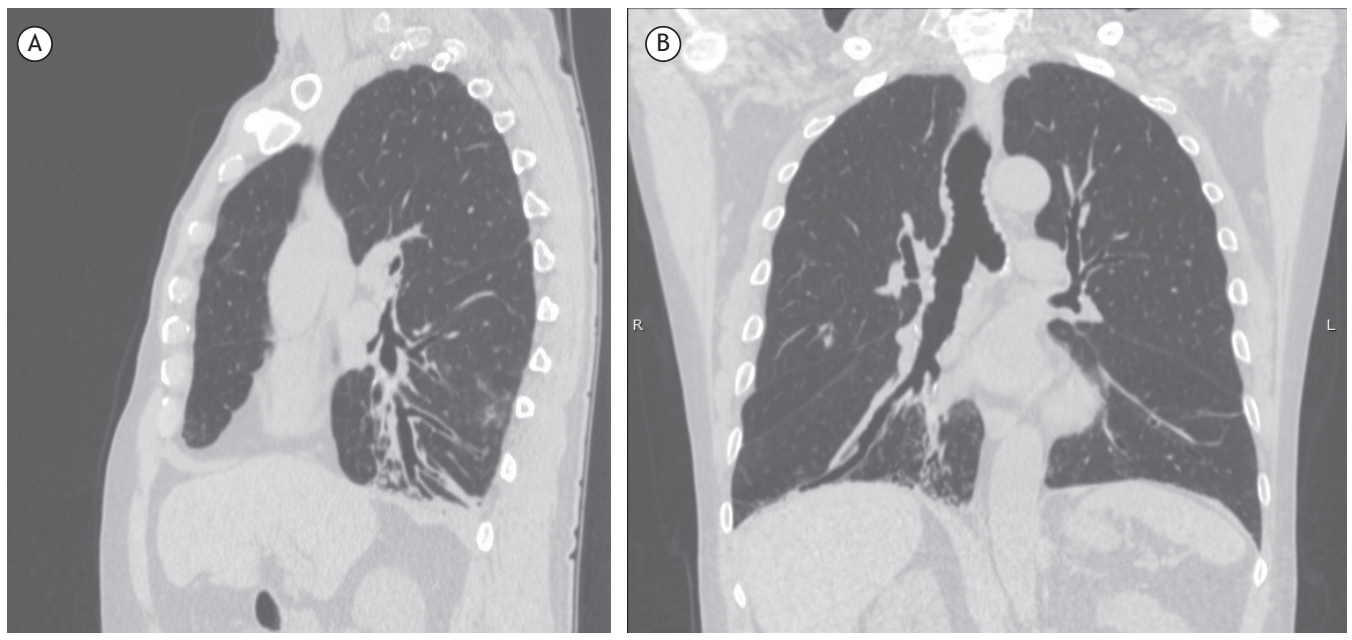

Figure 2. In A, sagittal chest CT scan demonstrating bronchiolectasis, atelectasis, and areas of ground-glass opacity in the lower lobes. In B, coronal chest CT scan demonstrating better visualization of bronchiolectasis in the right lower lobe. 

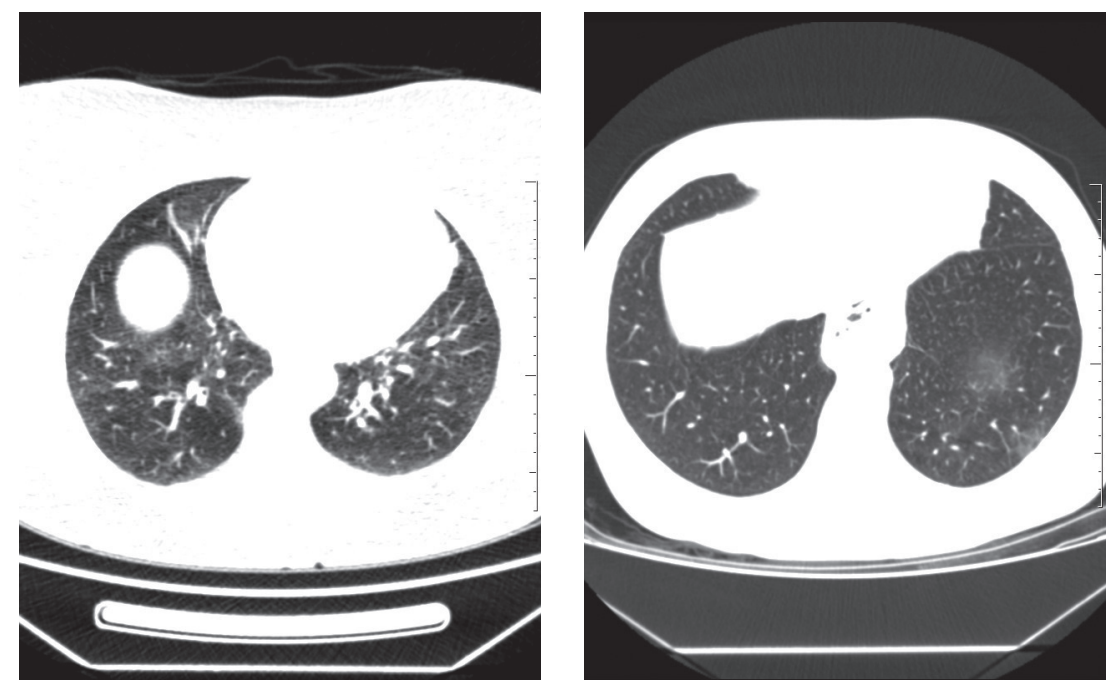

Figure 3. Axial chest CT scans showing areas of ground-glass attenuation in the left lower lobe.

as well as the varied sample characteristics. In this review, it was not possible to establish a consensus that could characterize a pattern of pulmonary aspiration in patients with dysphagia, and further studies on the subject are needed. Evidence suggests that chest CT findings in patients with aspiration are diverse; however, the articles mentioning the location of pulmonary findings detected that the findings were more prevalently distributed in the right lung and in lower lung zones.

\section{REFERENCES}

1. Marik PE. Aspiration pneumonitis and aspiration pneumonia. $N$ Engl J Med. 2001;344(9):665-71. https://doi.org/10.1056/ NEJM200103013440908

2. Makharia GK, Seith A, Sharma SK, Sinha A, Goswami P, Aggarwal A, et al. Structural and functional abnormalities in lungs in patients with achalasia. Neurogastroenterol Motil. 2009;21(6):603-8, e20.

3. Oue K, Mukaisho K, Higo T, Araki Y, Nishikawa M, Hattori T, et al. Histological examination of the relationship between respiratory disorders and repetitive microaspiration using a rat gastro-duodenal contents reflux model. Exp Anim. 2011;60(2):141-50. https://doi. org/10.1538/expanim.60.141

4. Matsuo K, Palmer JB. Anatomy and physiology of feeding and swallowing: normal and abnormal. Phys Med Rehabil Clin N Am. 2008;19(4):691-707, vii. https://doi.org/10.1016/j.pmr.2008.06.001

5. Karkos PD, Papouliakos S, Karkos CD, Theochari EG. Current evaluation of the dysphagic patient. Hippokratia. 2009;13(3):141-6.

6. Carucci LR, Turner MA. Dysphagia revisited: common and unusual causes. Radiographics. 2015;35(1):105-22. https://doi.org/10.1148/ rg.351130150

7. Martin-Harris $B$, Jones $B$. The videofluorographic swallowing study. Phys Med Rehabil Clin N Am. 2008;19(4):769-85, viii. https://doi. org/10.1016/j.pmr.2008.06.004

8. Kelly AM, Drinnan MJ, Leslie P. Assessing penetration and aspiration: how do videofluoroscopy and fiberoptic endoscopic evaluation of swallowing compare? Laryngoscope. 2007;117(10):1723-7. https:// doi.org/10.1097/MLG.0b013e318123ee6a

9. Bours GJ, Speyer R, Lemmens J, Limburg M, de Wit R. Bedside screening tests vs. videofluoroscopy or fibreoptic endoscopic evaluation of swallowing to detect dysphagia in patients with neurological disorders: systematic review. J Adv Nurs. 2009;65(3):47793. https://doi.org/10.1111/j.1365-2648.2008.04915.x

10. Franquet T, Giménez A, Rosón N, Torrubia S, Sabaté JM, Pérez C. Aspiration diseases: findings, pitfalls, and differential diagnosis. Radiographics. 2000;20(3):673-85. https://doi.org/10.1148/ radiographics.20.3.g00ma01673

11. Prather AD, Smith TR, Poletto DM, Tavora F, Chung JH, Nallamshetty $L$, et al. Aspiration-related lung diseases. J Thorac Imaging. 2014;29(5):304-9. https://doi.org/10.1097/RTI.0000000000000092

12. Higgins JPT, Green S, editors. Cochrane Handbook for Systematic Reviews of Interventions Version 5.1.0 [updated 2011 Mar]. The Cochrane Collaboration; 2011. Available from: http://www.cochrane- handbook.org

13. Moher D, Liberati A, Tetzlaff J, Altman DG; PRISMA Group. Preferred reporting items for systematic reviews and meta-analyses: the PRISMA statement. Int J Surg. 2010;8(5):336-41. Erratum in: Int J Surg. 2010;8(8):658. https://doi.org/10.1016/j.ijsu.2010.02.007

14. Hansell DM, Bankier AA, MacMahon H, McLoud TC, Müller $\mathrm{NL}$, Remy J. Fleischner Society: glossary of terms for thoracic imaging. Radiology. 2008;246(3):697-722. https://doi.org/10.1148/ radiol.2462070712

15. Simonelli M, Ruoppolo G, de Vincentiis M, Di Mario M, Calcagno P, Vitiello $C$, et al. Swallowing ability and chronic aspiration after supracricoid partial laryngectomy. Otolaryngol Head Neck Surg 2010;142(6):873-8. https://doi.org/10.1016/j.otohns.2010.01.035

16. Komiya K, Ishii H, Umeki K, Kawamura T, Okada F, Okabe E, et al. Computed tomography findings of aspiration pneumonia in 53 patients. Geriatr Gerontol Int. 2013;13(3):580-5. https://doi. org/10.1111/j.1447-0594.2012.00940.x

17. Lin L, Lv L, Wang Y, Zha X, Tang F, Liu X. The clinical features of foreign body aspiration into the lower airway in geriatric patients. Clin Interv Aging. 2014;9:1613-8.

18. Scheeren B, Marchiori E, Pereira J, Meirelles G, Alves G, Hochhegger B. Pulmonary computed tomography findings in patients with chronic aspiration detected by videofluoroscopic swallowing study. $\mathrm{Br}$ Radiol. 2016;(1063):20160004. https://doi.org/10.1259/bjr.20160004

19. Butler SG, Clark H, Baginski SG, Todd JT, Lintzenich C, Leng X. Computed tomography pulmonary findings in healthy older adult aspirators versus nonaspirators. Laryngoscope. 2014;124(2):494-7. https://doi.org/10.1002/lary.24284

20. Pikus L, Levine MS, Yang YX, Rubesin SE, Katzka DA, Laufer I, et al. Videofluoroscopic studies of swallowing dysfunction and the relative risk of pneumonia. AJR Am J Roentgenol. 2003;180(6):1613-6. https://doi.org/10.2214/ajr.180.6.1801613

21. Torres A, Serra-Batlles J, Ferrer A, Jiménez $P$, Celis R, Cobo E, et al. Severe community-acquired pneumonia. Epidemiology and prognostic factors. Am Rev Respir Dis. 1991;144(2):312-8. https:// doi.org/10.1164/ajrccm/144.2.312

22. Moine P, Vercken JB, Chevret S, Chastang C, Gajdos P. Severe community-acquired pneumonia. Etiology, epidemiology, and prognosis factors. French Study Group for Community-Acquired Pneumonia in the Intensive Care Unit. Chest. 1994;105(5):1487-95. https://doi.org/10.1378/chest.105.5.1487 
23. Serra-Prat M, Palomera M, Gomez C, Sar-Shalom D, Saiz A, Montoya $J G$, et al. Oropharyngeal dysphagia as a risk factor for malnutrition and lower respiratory tract infection in independently living older persons: a population-based prospective study. Age Ageing. 2012;41(3):37681. https://doi.org/10.1093/ageing/afs006

24. Chaves Rde D, Carvalho CR, Cukier A, Stelmach R, Andrade CR Symptoms of dysphagia in patients with COPD. J Bras Pneumol. 2011;37(2):176-83.

25. Augusto DK, Miranda LF, Cruz CE, Pedroso ER. Comparative study of elderly inpatients clinically diagnosed with community- acquired pneumonia, with or without radiological confirmation. $J$ Bras Pneumol. 2007;33(3):270-4. https://doi.org/10.1590/S180637132007000300007

26. Marik PE, Kaplan D. Aspiration pneumonia and dysphagia in the elderly. Chest. 2003;124(1):328-36. https://doi.org/10.1378/ chest.124.1.328

27. Leder SB, Murray JT. Fiberoptic endoscopic evaluation of swallowing Phys Med Rehabil Clin N Am. 2008;19(4):787-801, viii-ix. https://doi. org/10.1016/j.pmr.2008.05.003 